\title{
Plasmacytoma of the larynx
}

Tanweer F, Sadlak M, Prashanth S. United Lincolnshire Hospitals NHS Trust, Lincoln, UK

\section{Abstract:}

Background: Solitary extramedullary plasmacytoma is a rare condition and accounts for $\sim 3 \%$ of plasma cell malignancies ${ }^{1}$. Patients presents with symptom and signs related to the location of lesion.

Objective: We report two rare cases of extramedullary plasmacytoma of the larynx treated in our department in last 4 years.

Method: Case report and review of the literature concerning the clinical presentation and management.

Results: Our patient presented with upper airway symptoms. On fibre-optic examination we found innocent looking polypoid mass. Patient didn't have any systemic features of myeloma on thorough investigation. Patients were treated with radiotherapy under the guidance of H\&N and hematology MDT. Patients have so far not shown any signs of local recurrence or systemic disease.

Conclusion: Although these tumours commonly present with significant airway symptoms, they respond very well to radiotherapy. $50 \mathrm{GY}$ in 25 fractions with IMRT seems sufficient with least long term morbidity ${ }^{2}$.
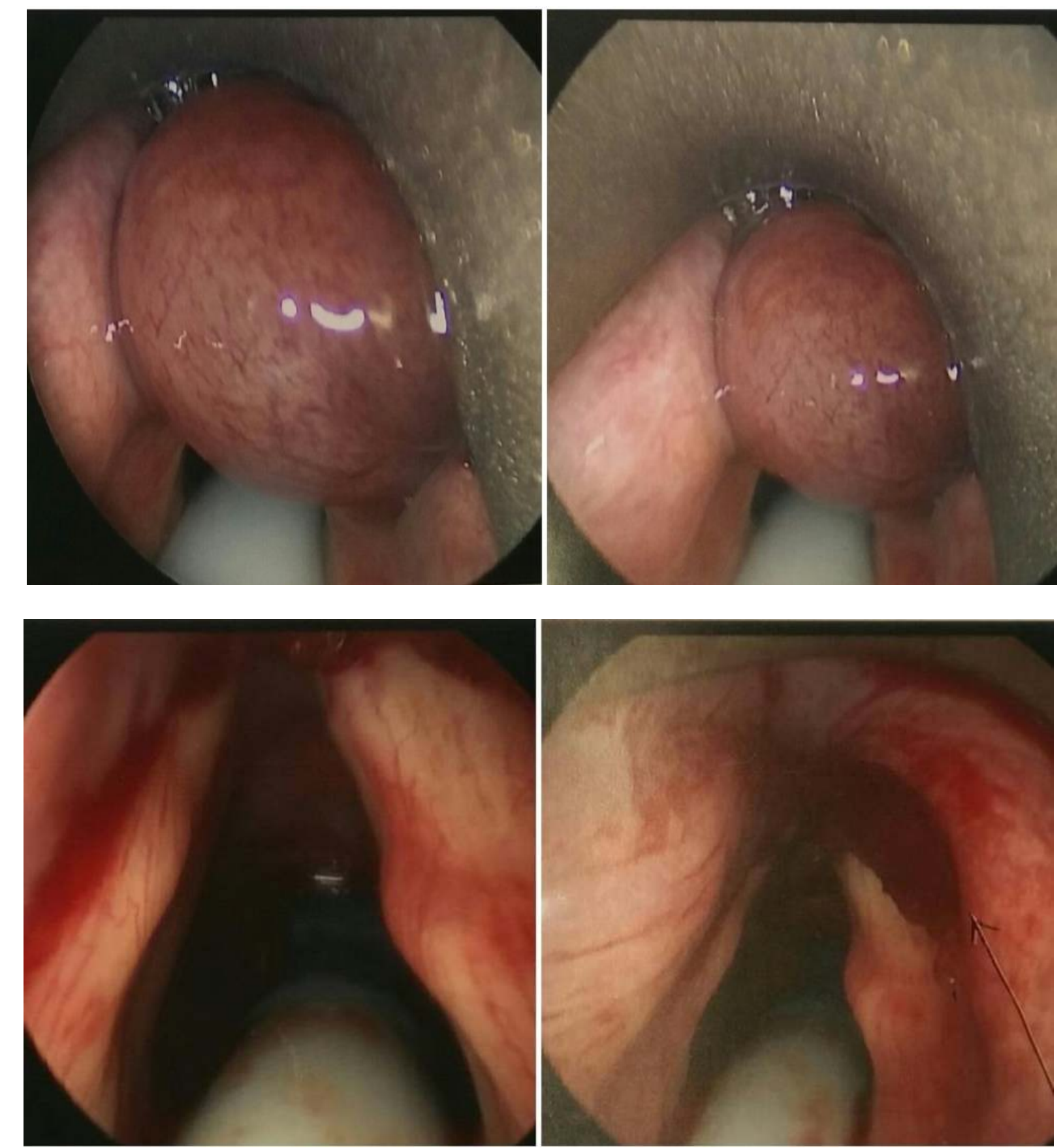

Pre \& Post excision biopsy

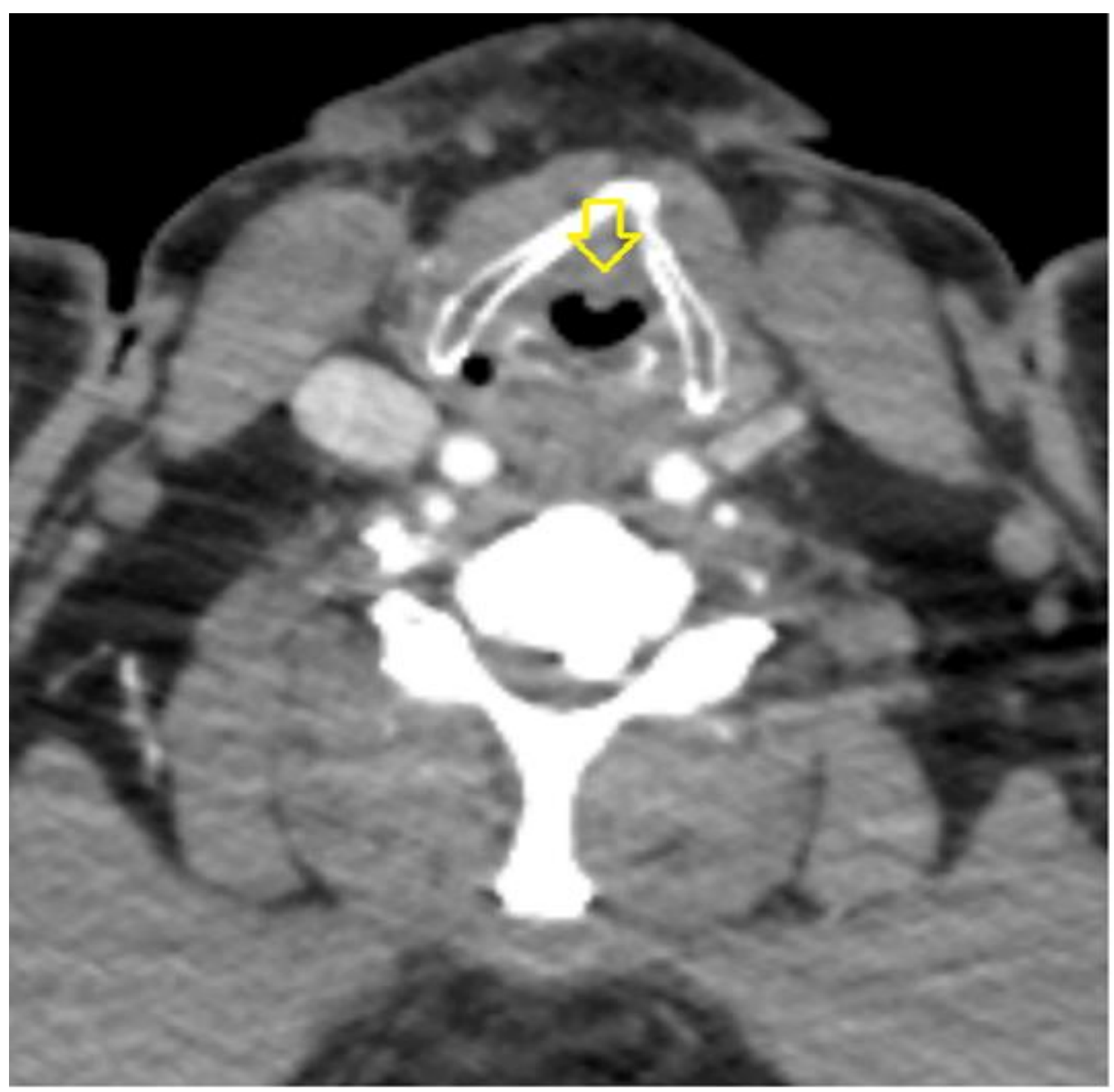

CT scan Neck

\section{Reference:}

1. Soutar R, Lucraft H, Jackson G, et al; Guidelines Working Group of the UK Myeloma Forum; British Committee for Standards in Haematology; British Society for Haematology. Guidelines on the diagnosis and management of solitary plasmacytoma of bone and solitary extramedullary plasmacytoma. Br J Haematol. 2004;124:717-26

2. Dores GM, Landgren O, McGlynn KA, et al. Plasmacytoma of bone, extramedullary plasmacytoma, and multiple myeloma: incidence and survival in the United States, 1992-2004. Br J Haematol 2009; 144:86. 